\title{
STI vaccines: a review
}

\author{
Paudel S, Dhali T \\ Department of Dermatology and Venereology, B. \\ P. Koirala Institute of Health Sciences, Dharan
}

\begin{abstract}
The word vaccine is derived from the Latin vacca meaning cow. Vaccines were named from Edward Jenner's use of cowpox virus inoculation against smallpox in 1796. A vaccine is a preparation of live, attenuated, or killed microorganisms or antigenic proteins derived from them, administered for the prevention, amelioration, or treatment of an infectious disease. Virulence factors, such as adhesion factors and capsules, are preferred vaccine targets.

Protective immunity relies on both humoral and cellular immune factors. Antigen recognition stimulates the activation and clonal expansion of antigen-specific B lymphocytes, which may ultimately protect against a secondary challenge as "memory B cells". Antibody-mediated protection may involve preexisting antibody, such as secretory $\operatorname{IgA}(\operatorname{sIgA})$ at the mucosal surface (sterilizing immunity) and/or a robust secondary immune response by serum IgG. After the expansion phase of CMI, $90 \%$ of activated cells die by activation induced apoptosis. The remaining cells enter a memory phase, which can be maintained for long periods. These "memory T cells" are either resting or effector cells. Resting cells are found in the major lymphoid organs whereas effector cells reside in peripheral tissues. Effectors respond rapidly with cytokines and direct cytolytic activity.

The goal of vaccination is to provide at least the same degree and duration of protection as natural infection without the accompanying clinical illness. A good vaccine produces a humoral, cellular, and innate immune response protective against both clinical disease and reinfection for a lifetime with minimal immediate adverse effects and no delayed effects.
\end{abstract}

\section{Introduction}

In human history, no infectious disease has been eliminated (incidence $=0.5 / 100,000$ ) without an effective vaccine. Vaccines against sexually transmitted diseases (STDs) have incredible potential to save lives, reduce morbidity, decrease global STD expenditures, reduce HIV spread, prevent AIDS, and contribute to improved reproductive health. STD vaccines will also circumvent many of the very significant challenges to nonvaccine STD prevention and control strategies, including behavioral change, societal impediments, biological obstacles, and translating intervention-trial efficacy into real-world effectiveness.

With the global incidence of curable STDs at 300350 million and the prevalence of viral STDs over 1 billion $^{1,2}$, the potential for STD vaccines, even imperfect ones, to reduce morbidity and mortality is vast. Syphilis, gonorrhea, chlamydia, and pelvic inflammatory disease (PID) together rank second behind obstetrical causes among women 15-44 years of age in developing countries as a cause of disability-adjusted life years (DALYs) and HIV ranks fourth. ${ }^{1,3}$ Among men, HIV is the leading cause of healthy life lost in this same age group. Tuberculosis, the most common AIDS-associated opportunistic infection in the world, ranks second in men and third in women as the cause of DALYs. ${ }^{3}$

Effective STD vaccines could change the face of HIV and AIDS also as these are known risk factors of acquisition and propagation of HIV. 4,5

STDS are difficult to diagnose because of lack of symptoms, nonspecific symptoms, problems collecting specimens, and performing laboratory tests in the high-risk, and the lag time to complications. Most herpes infections are spread by asymptomatic and unaware index patients. Because STD complications occur months or years after the initial, often unrecognized, infection, STDs are often not associated in the public mind with serious illness. Treatment, a critical component in control, is restricted to bacterial and protozoan STDs. There are no cures for HPV, HBV, HSV, or HIV. Effective suppressive therapies for HIV and HSV are available but these are not accessible for patients in most of the world. For decades, effective prevention, treatment, and control strategies have been available for the "curable" STDs (gonorrhea, syphilis, chlamydia, and trichomonas), but this has not reduced their overall global incidence because of poor access and antibiotic resistance. STD vaccine delivery programs would be easier to implement, evaluate, and maintain, narrowing the dichotomy between 
intervention-trial efficacy and real-world effectiveness. 6,7

\section{Licensed STD vaccines}

Currently, two vaccines are licensed by the FDA for prevention of STDs, vaccines for HBV and HPV infections.

\section{Hepatitis B virus}

A hepatitis B virus (HBV) vaccine has been available for over 20 years. The initial 1982 preparation was purified surface antigen or HBV envelope proteins from the plasma of infected individuals. This was replaced in 1986 by a genetically engineered vaccine manufactured in a yeast recombinant (S. cerevisiae) expressing the gene for the surface antigen. This yeast-derived vaccine is immunogenic, safe and cost-effective in preventing $\mathrm{HBV}$ infection in neonates, children, and adults. An additional $\mathrm{HBV}$ vaccine is derived from mammalian cells using an identical process.

Seroprotection after vaccination is defined as antiHBs status $=10 \mathrm{mIU} / \mathrm{mL}$. This is achieved in over $95 \%$ of young vaccinees. HBV vaccines are well tolerated with minimal side effects. Symptomatic hepatitis B infection is extremely rare after successful immunization even though anti-HBs levels may become nondetectable in up to $50 \%$ of individuals within 5-10 years. Immunization also prevents perinatal infection in infants born to HBsAg-positive mothers. The usual immunization course is three doses including a final booster at least 4-6 months after the initial two-dose primary series. Routine childhood and infant vaccination is now the goal of the WHO, CDC, and most official bodies.

Even if everyone were immunized against HBV today, 350 million chronically infected carriers would still need treatment. The success of postexposure immunization has raised the possibility of a therapeutic HBV vaccine. Additionally, HBsAg clearance has been observed in individuals who received bone marrow transplants from HBV-immune donors. ${ }^{10}$ This correlated with detection of CD4 $+\mathrm{T}$ cell reactivity against $\mathrm{HBc}$ in the blood. These and other data suggest that therapeutic vaccination should include

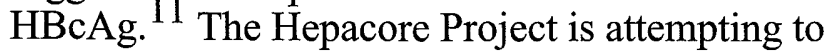
develop a therapeutic vaccine based on chimeric HBc VLPs. 2

To induce a $\mathrm{CD} 8+\mathrm{T}$ cell response, studies have focused on DNA immunization and HBV polymerase, a highly immunogenic $\mathrm{CD}_{10}+$ target essential for early virus replication. ${ }^{10}$ These approaches is thought to prevent the hepatic damage. 10
Some have suggested strategies to optimize the immune response to enable a therapeutic vaccine to be successful; for instance, inhibition of viral replication by antiviral drugs. ${ }^{11}$ Lamivudine treatment has been associated with improved HBVspecific helper and cytotoxic $\mathrm{T}$ cell function in chronically HBV-infected individuals. 11,13

\section{Human papillomavirus}

Human papillomavirus (HPV) type 16 was first identified as a significant factor in the pathogenesis of preinvasive and invasive cervical cancer in 1983. Over 200 types have now been described; 40 can infect the genital tract and more than 20 types have been associated with cervical cancer. ${ }^{14}$

Seventy percent of cases of cervical cancer are associated with types 16 and 18 ; and $90 \%$ of genital warts are associated with types 6 and 11 . In 1991, papillomavirus-like particles were created in the laboratory allowing accelerated vaccine research. These virus-like particles (VLPs) are empty viral capsids, which copy the structure of the natural virion but are devoid of DNA. They are noninfectious but generate a potent immune response.

In 2002, the remarkable efficacy of a preventive $\mathrm{HPV}-16$ vaccine was demonstrated in a phase II randomized, multicenter, double-blind study involving 2391 young women 15-26-yearold. $14,15,16$ Using VLPs of the L1 protein in the viral capsid, the vaccine was protective against preinvasive disease (efficacy $=100 \%$ ), persistent HPV-16 infection (efficacy $=100 \%$ ) and transient HPV infection (efficacy $=91 \%$ ). Efficacy against persistent infection remained $100 \%$ even including participants who had violated the study protocol. The three-dose regimen had few side effects and generated an antibody response in $99.7 \%$. At month 7 , the mean antibody level was 58.7 times as high as women with natural infection. 15 Immunogenicity bridging studies have demonstrated anti-HPV titers two-to-threefold higher in boys and girls 9-15 years of age compared to females over 15 . The antibody levels generated in girls are constant over the 9 to 11 year age range but fall off significantly, when the vaccine is given at $12-13$ years of age. 17,18

Highly consistent results were subsequently obtained from a bivalent (HPV-16/18) vaccine in a phase IIb trial ${ }^{19}$ and a quadrivalent (HPV6/11/16/18)vaccine in one phase II and two phase III trials. ${ }^{20,21}$ Participants were from North America and South America, Europe, and the AsiaPacific. The bivalent vaccine (Cervarix ${ }^{\circledR}$, GlaxoSmithKline Biologicals) is manufactured in an baculovirus/insect cell expression system whereas the quadrivalent vaccine (Gardasil $\AA$, 
Merck and Co., Inc.) uses a yeast system (Saccharomyces cerevisiae) ${ }^{14,16}$ Cervarix ${ }^{\circledR}$ includes an adjuvant composed of $500 \mu \mathrm{g}$ of aluminum hydroxide with $50 \mu \mathrm{g}$ of 3 -deacylated monophosphoryl lipid A (AS04) ${ }^{14,16}$ Gardasil ${ }^{\circledR}$ includes an adjuvant of $225 \mu \mathrm{g}$ of aluminum hydroxyphosphate sulfate..$^{20}$ The vaccines should be stored at $+2^{\circ} \mathrm{C}$ to $+8^{\circ} \mathrm{C}$ and not allowed to freeze.

In mid-2007, the updated results of four randomized, double-blind, placebo-controlled trials in individuals over 15 years of age involving the quadrivalent vaccine were reported. . $^{22,23,24,25}$

\begin{tabular}{|l|c|c|c|c|l|}
\hline \multirow{2}{*}{ Clinical endpoint } & \multicolumn{2}{|l|}{ Vaccine } & \multicolumn{2}{l|}{$\begin{array}{l}\text { Vlacebo } \\
\text { Vaccine efficacy } \\
\text { (95\% CI) }\end{array}$} \\
\cline { 2 - 6 } & No. of women & $\begin{array}{l}\text { No.0f } \\
\text { cases }\end{array}$ & No. of women & $\begin{array}{l}\text { No. of } \\
\text { cases }\end{array}$ & \\
\hline $\begin{array}{l}\text { HPV 16/18-related CN } \\
\text { 2/3 or AIS }\end{array}$ & 8487 & 0 & 8460 & 53 & $100 \%(92.9-100)$ \\
\hline HPV 16/18 related VIN 2+ & 7897 & 0 & 7899 & 8 & $100 \%(41.4-100)$ \\
\hline $\begin{array}{l}\text { HPV 16/18 related } \\
\text { ValN 2+ }\end{array}$ & 7897 & 0 & 7899 & 5 & $100 \%(<0-100)$ \\
\hline $\begin{array}{l}\text { HPV 6/11/16/18-related } \\
\text { genital warts } \\
\text { (condyloma) }\end{array}$ & 7897 & 1 & 7899 & 91 & $98.9 \%(93.7-100)$ \\
\hline
\end{tabular}

Gardasil ${ }^{\circledR}$ generates cross-reactive and crossprotective antibody concentrations against HPV31 and HPV-45, as well. ${ }^{17}$ Gardasil® has shown partial cross-protection against persistent infection (combined efficacy 27\%) and against CIN2/3 and AIS (combined efficacy 39\%) caused by 10 nonvaccine oncogenic HPV types (HPV31/33/35/39/45/51/52/56/58/59). ${ }^{26}$

A cohort of Gardasil $®$ recipients $(n=241)$ followed for 60 months after dose 1 exhibited high, sustained vaccine efficacy with no evidence of waning immunity. ${ }^{14,16}$ Antibody titers peaked 30 days after dose 3 , declined until month 18 , and then plateaued for the 5 years of follow-up. Similar results have been documented for a Cervarix ${ }^{\circledR}$ cohort followed for 4.5 years. ${ }^{20}$ Both vaccines were safe and welltolerated. No adverse effects were seen in the pregnant vaccine recipients or their breastfed infants. ${ }^{65,14}$ But neither vaccine is recommended in pregnancy, for males, or for females older than 26 or younger than 9 years. HPV vaccine studies in each of these groups are underway and no additional risks are anticipated. ${ }^{20}$

By the end of 2006, Gardasil ${ }^{\circledR}$ was licensed in 49 countries, including FDA approval on June 9, 2006. Cervarix ${ }^{\circledR}$ was licensed in Australia in May 2007.

By vaccinating only girls before they become sexually active, one might expect an $85 \%$ reduction in cervical cancer, a 44-70\% reduction in abnormal Pap smears attributable to HPV, and a 95\% reduction in cervical cancer deaths. ${ }^{27}$

Oncogenic HPV can cause several other cancers including penile, oropharyngeal, laryngeal, oral and anal neoplasms. This argues for vaccinating boys, men, and women outside 9-26 years of age. Plus, women can acquire HPV at any age. Merck is sponsoring a clinical trial of Gardasil ${ }^{\circledR}$ in 4000 men, including 500 self-identified gay men. Lastly, vaccine formulations including HPV 6 and 11 will prevent most genital warts.

Amid the euphoria, some have called for second generation HPV vaccines to addresses problems with the current VLP products.

An HPV DNA vaccine would be simpler to produce; an HPV viral vector vaccine might be compatible with mucosal delivery; and an HPV L2 vaccine would likely be broadly cross-neutralizing. ${ }^{28} \mathrm{~A}$ combined prophylactic and therapeutic HPV vaccine using L1/L2 and E6/E7 chimeric VLPs is feasible.

Progress toward a therapeutic HPV vaccine has not been as dramatic although three therapeutic vaccine candidates are in phase II trials. Most research has focused on the early viral proteins (E1, E6, and E7) that are required for viral DNA replication, maintenance, and papilloma formation.

\section{STD vaccines in development}

Of the remaining STDs, vaccine research is most advanced for HSV, N. gonorrhoeae, T. pallidum, and $\mathrm{C}$. trachomatis.

\section{Herpes simplex virus}

Research into herpes vaccination has been ongoing for over 80 years. Predictably, the optimal vaccine would induce both humoral and cellular immunity; however, for HSV, the principal humoral and CMI mediators of infection are poorly understood. ${ }^{29,30,31}$ Killed virus vaccine candidates have failed and the focus for HSV vaccine development has shifted to:

(1) Replication-incompetent mutant virus vaccines are derived from infectious HSV viral strains missing a gene essential to the reproductive cycle. In two randomized controlled trials, recurrences were prevented in $37.5 \%$ and $43.5 \%$ with this vaccine. ${ }^{32,33}$ 
(2) Replicating vector vaccine candidates involve HSV gene insertion encoding immunogenic proteins into a replication-competent viral or bacterial vector, such as vaccinia, adenovirus, and Salmonella. ${ }^{34}$ Human trials with this vaccine have not been completed.

(3) Subunit vaccines centered on glycoproteins D and B. Both are highly conserved in the majority of HSV strains (over $98 \%$ in the case of gD) and both stimulate neutralizing antibody, antibodydependent cellular cytotoxicity, and CD4+/CD8+ virus-specific immune responses. ${ }^{35}$ Studies demonstrated significant protection from symptomatic herpes $(73 \%, p=0.01$ and $74 \%, p$ $=0.02$ in 2 studies) in women without preexisting antibody to HSV-1 or HSV-2 (34).There was a nonsignificant trend to reduced HSV infection in HSV- 1 and HSV-2 negative women $(46 \%$ and $39 \%$ ) but no effect in HSV-1 seropositive women or men.

(4) DNA vaccines, could stimulate multiple arms of the immune system using a mixture of plasmids encoding various peptides. ${ }^{30}$

\section{HIV vaccines}

In 2006, the HIV/AIDS pandemic marked its 25th year. To date, roughly 60 million people have been infected and 20 million have died of AIDS. Approximately 15,000 people become infected with HIV every day. Treatment will not prevent events that happen very early after infection. Thus, there is an urgent need for effective and affordable prevention strategies.

\section{Approaches to prophylactic vaccines}

\section{Neutralizing antibodies}

More than $85 \mathrm{HIV}$ vaccine trials involving over 30 products have been conducted to date. Initial HIV vaccines targeted the production of neutralizing antibodies. These antibodies not only bind to infectious HIV but do so in a manner that prevents productive interaction with target cells, thereby "neutralizing" HIV infectivity.

Several monoclonal antibodies have been tried for this purpose. F105 and b12, which are specific for the CD4 binding site on gp120;2G12, which recognizes a complex epitope on gp120; and 2F5 and $4 \mathrm{E} 10$, which recognize linear epitopes on gp41. The ease with which these epitopes could be incorporated into a vaccine is unclear. For example, the b12 monoclonal has an unusual extended antigen-binding finger that accesses a normally recessed epitope on gp120 and blocks CD4 binding. ${ }^{36}$ The feasibility of targeting gp41 domains involved in virus fusion with the target cell, as $2 \mathrm{~F} 5$ and 4E10 do, may be limited by steric hindrance and by the rapidity of the fusion process. $^{36,37}$

When three of these monoclonals were tested in vitro against a panel of newly transmitted clade $\mathrm{B}$ isolates, 4E10 alone neutralized all isolates, $2 \mathrm{~F} 5$ neutralized $80 \%$, and $2 \mathrm{G} 12$ neutralized $37 \%$. The combination of $\mathrm{b} 12,2 \mathrm{G} 12,2 \mathrm{~F} 5$, and $4 \mathrm{E} 10$ has shown strong cross-clade neutralization against clades $\mathrm{B}, \mathrm{C}, \mathrm{A}$, and $\mathrm{D}$ in vitro. ${ }^{39}$

Phase 1 safety studies have been conducted with four of these monoclonals. They have been found in adults to be safe and well tolerated, with in vivo concentrations in the range of those that cause $>99 \%$ neutralization in vitro. ${ }^{39}$ Initial clinical studies of passive immunization with broadly neutralizing monoclonal antibodies have not been found satisfactory. ${ }^{40}$ Current vaccine approaches to eliciting broad neutralization include the construction of immunogens that preferentially expose epitopes capable of inducing neutralizing antibodies. Selective mutagenesis has been used in an attempt to increase the response to neutralizing epitopes while diminishing that to other, often more dominant, nonneutralizing epitopes. ${ }^{41}$. Monoclonal antibodies in HIV-infected individuals have not resulted in significant reduction in viral load. ${ }^{40}$

\section{Cellular immunity}

Most ongoing trials of HIV vaccine candidates involve products that aim to induce HIV-specific CTLs. These cells recognize HIV epitopes displayed on cell surfaces in conjunction with HLA. Thus, these immune effector cells recognize infected cells but not free virus. They limit the spread of infection by destroying infected cells via apoptosis, or by secreting chemokines and cytokines that interfere with subsequent rounds of infection. Transmission decreases with reductions in plasma viral load and may be completely prevented when viral load drops below 1500 copies $/ \mathrm{mL}$.

\section{Clinical trials of CTL vaccines}

In 2007, the majority of HIV vaccines in clinical testing elicit primarily CTL-based responses. Many vaccines based on viral vectors, such as poxviruses, adenovirus, and alphaviruses, have been tested in humans and found to be safe. ${ }^{42,43,44}$ While many of these products have shown limited immunogenicity in humans, in phase 1 and 2 trials several adenovirus candidates induce high-level CTL responses as measured in chromium-release CTL assays, or in ELISpot or intracellular cytokine staining assays, which measure HIV-specific T cell activity. HIV vaccines based on DNA plasmids 
also show a favorable safety profile, although these vaccines have been less immunogenic in vitro than was predicted by preclinical tests in nonhuman primates.

\section{Clinical trials of vaccines delivered mucosally}

Natural history studies and challenge studies in nonhuman primates have shown that mucosal responses are of potential importance in protection against HIV acquisition. Observational studies conducted in highly exposed persistently seronegative (HEPS) women have reported the presence of HIV-specific IgG and IgA in vaginal secretions. ${ }^{45,46,47,48,49}$

Clinical development of these vaccines are desired to balance the need to induce immunity at mucosal surfaces with safety concerns that limit some mucosal applications, such as potential neurotoxicity of replication-competent viral vectors delivered nasally. Initial clinical studies using mucosal delivery of canarypox HIV vaccine (ALVAC 205) to the nose, mouth, vagina, or rectum followed by gp120 delivered intramuscularly (IM) demonstrated that this approach was safe but not effective for eliciting a mucosal immune response. ${ }^{50}$ This area remains one of active research; several candidates, including a replication-competent adenovirus vector, are under development.

\section{HIV vaccine design strategies}

\section{Live, attenuated vaccines:}

Early attempts to replicate the successes of small pox and polio in HIV vaccine development investigated the efficacy of attenuated SIV vaccine candidates. The first of these candidates, SIV1A11, was produced by protracted passage in vitro. ${ }^{51}$ Vaccination with this attenuated strain did not result in disease but showed limited efficacy in protecting vaccinated macaques against the challenge with pathogenic SIV. These observations were apparently replicated in humans; a benign clinical course was reported for a group of six individuals who were exposed through blood transfusion to HIV carrying a deletion in nef. However, the safety of this approach was called into question by late-onset immunosuppression in three of the transfusion recipients.

\section{Inactivated HIV vaccines}

Attempts to make these vaccines were made due to the success of rabies and polio vaccines. Of the nine macaques immunized with formalininactivated SIV and adjuvant, eight were protected when challenged with 10 animal-infectious doses of SIV 2-3 weeks after boosting. ${ }^{52}$ These promising results were not replicated, however, when similarly immunized animals were challenged with SIV that varied slightly from the immunizing strain or when challenge occurred after the peak response immunity was directed against cell surface antigens retained in virions. Loss of HIV- or SIV-specific antigens from the viral surface in the process of inactivation is the drawback. Human studies are not done.

\section{Peptides/subunits}

Early efforts focused on use of gp120 immunogens to elicit antienvelope antibodies are underway. Experiments in nonhuman primates indicated that neutralizing antibodies were elicited by this route, and it was hoped that this approach could be used to induce sterilizing immunity (i.e., that it would prevent infection completely). However, the majority of experiments indicated that the antibody response was narrowly limited to the HIV strain used in the vaccine (or one that resembled it closely) and that this approach did not offer protection from challenge with primary isolates or other heterologous strains. The first trial used envelop antigens from two different subtype B strains and was tested among 5403 volunteers in the United States, Canada, and Europe. This vaccine did not provide protection against infection (vaccine efficacy $=6 \%, 95 \% \mathrm{CI}=[-17 \%, 24 \%]$ ) and did not affect HIV disease course in participants who became infected. ${ }^{53}$

\section{DNA vaccines}

Another recent approach involves the use of DNA plasmids to deliver DNA coding for HIV proteins or HIV epitopes. These plasmids do not integrate into the host cells of vaccinated individuals but rather remain episomal and act as expression vectors, producing peptides that can induce cellular immunity. Although immunization using DNA plasmids with HIV inserts elicited substantial cellular responses in mice and nonhuman primates, these products have been poorly immunogenic in humans. One attempt to increase immune response has included the use of genetic adjuvants, specifically the coadministration of DNA vectors coding for cytokines, most notably IL-12 and IL15. In a second approach, DNA is used as the prime in a heterologous prime-boost strategy, with a protein or vector vaccine as the boost. Initial experiments using this approach in nonhuman primates were very promising. Animals primed with DNA and boosted with pox-virus vaccines (MVA or fowlpox) showed strong CD8 T cell responses. While this approach did not prevent SHIV infection in vaccinated animals after parenteral or mucosal challenge, it was associated with control of viral replication and amelioration of clinical course. ${ }^{54}$ 


\section{Viral vectors}

Perhaps the most widely used approach at present is the use of recombinant viral or bacterial vectors as "Trojan horses" carrying HIV genetic sequences. These vaccine candidates enter the host cell, where they elicit immunity to the vector and to the product of the HIV gene they carry. This approach is useful for eliciting cellular immunity since the HIV genes are transcribed within the targeted cell and thus enter the HLA class 1 processing pathway. Poxvirus and the adenovirus are the most commonly used vectors. They are highly immunogenic and produce cell mediated response.

Canarypox is the HIV vaccine vector studied most extensively in humans to date. During the past 15 years, over 30 phase 1 and 2 trials involving more than 1500 participants have been conducted with first- and second-generation canarypox HIV vaccines (such as ALVAC).$^{55}$ Responses seen in different trials did not meet the preset immunogenicity criteria and plans for an efficacy trial of this regimen were therefore abandoned. ${ }^{56}$ Several preclinical and clinical studies are ongoing with the aim of optimizing the immunogenicity of these vectors. In Thailand, a phase 3 trial of a canarypox vector (VCP 1521) containing the HIV1 clade B env, gag, and protease genes, in combination with gp120 (clades B and E) completed enrollment in January 2006; follow-up is ongoing and is expected to end in mid-2009. ${ }^{57}$

The most promising candidates at present are HIV vaccines constructed using adenovirus vectors. These viral vectors are rendered replicationdefective by mutations and the deletion of an adenovirus gene. Two different products are in advanced clinical testing at present. The first, produced by Merck, contains an admixture of three adenoviruses containing codon-optimized subtype B gag, pol, or nef genes, respectively. These three HIV genes are conserved $(80 \%$ to $>90 \%$ conserved) across subtypes. The Merck adenovirus vectors containing gag alone or a trivalent preparation containing gag, pol, and nef produce robust cytotoxic CD8+ T cell responses in macaques (500-1000 ?-interferon-producing cells/106 PBMCs after vaccination with 1011 viral particles). 58,59

The second Ad5 candidate, developed by the U.S. National Institutes of Health's (NIH) Vaccine Research Center (VRC), is designed to provide multiclade protection. It is an admixture of four adenoviruses, one of which contains a subtype B gag-pol gene fusion. The other three adenoviruses contain subtype A, B, or C envelope genes. This VRC construct has also elicited strong humoral and cellular responses in macaques. The magnitude and breadth of the response was improved by prior priming of the product with the DNA plasmids discussed above. ${ }^{60}$

But unfortunately in September 2007, vaccinations were discontinued in the two test-of-concept efficacy trials of the trivalent HIV adenovirus type 5 (Ad5) vaccine produced by Merck and Co., Inc. (MRK Ad5 HIV-1 gag/pol/nef). The initial interim analysis of STEP study data was designed to look at vaccine effects in men without evidence of prior natural infection with Ad5. Subsequent, posthoc analyses looked at data from all men, with or without prior exposure to Ad5. These analyses suggested that risk of acquiring HIV infection may have been increased among vaccine recipients who had pre-existing immunity to the adenovirus vector. All HIV seroconversions except one occurred among male volunteers, so analyses were limited to men. Overall, $49 \mathrm{HIV}$ infections occurred in the 914 male vaccine recipients and 33 in the 922 male placebo recipients. However, stratification of the results by pre-existing Ad5 immunity revealed that among men with high Ad5 titers (>200 units), 21 of 392 vaccinees and 9 of 386 placebo recipients became HIV infected, while among men with low Ad5 titers (= 200 units), 28 of 522 vaccinees and 24 of 536 placebo recipients seroconverted. In the 776 men with no prior immunity to Ad5, the case split was balanced-20 infections were seen in each group. Among all men in the trial, the geometric mean RNA levels among vaccinees $(\sim 29,000$ copies $/ \mathrm{mL})$ was similar to that among placebo recipients $(\sim 38,000$ copies $/ \mathrm{mL}){ }^{61,62}$

The implications of these findings for efficacy testing of the second Ad5 HIV vaccine candidate, produced by the U.S. National Institute of Health's Vaccine Research Center, are unclear at this time.

\section{Adjuvants}

Another area of ongoing research is adjuvanting of HIV vaccine candidates. Many of the current vaccine strategies do not produce immune responses that are robust, long-lived and appropriately focused on production of neutralizing antibodies or cytotoxic responses. Adjuvants could overcome this by targeting the antigen to antigenpresenting cells or increasing immune response by stimulating production of cytokines and costimulatory molecules or both. Adjuvants such as polymeric microspheres (e.g., polylactidecoglycolide or PLG) and many mre have been tested with HIV vaccine candidates to increase immune response through facilitating interactions with antigen-presenting cells with hopeful outcomes. ${ }^{63}$ The complementary approach, induction of relevant cytokines and upregulation 
of costimulatory molecules, is used by other adjuvants such as $\mathrm{CpG}$, unmethylated cytosinceguanine dinucleotides, which acts as a ligand for toll-like receptor 9 (TLR9). ${ }^{64}$ Stimulation of TLRs in turn enhance and direct immune response. A related approach is the administration of vaccine candidates with costimulatory molecules such as I1-12, IL-15, or granulocyte-macrophage stimulating factor (GM-CSF) in an attempt to manipulate the immune response and increase cell-mediated immunity to the coadministered HIV vaccine antigen. ${ }^{65}$

\section{Bacterial vaccines}

\section{Neisseria gonorrhoeae}

Progress in N. gonorrhoeae vaccine development has been hindered by the lack of a credible animal model of mucosal disease, marked antigenic diversity between strains, and antigenic variation within strains over time. ${ }^{66}$ Trials of a formalin killed, piliated whole organism vaccine, a gonococcal purified pilus vaccine, and a recombinant protein I (Por) vaccine have all failed. ${ }^{67}$ ?

\section{Chlamydia trachomatis}

Despite active preclinical research and development for over 20 years, no vaccine for the prevention of sexually transmitted C. trachomatis has entered clinical trials. Vaccines for trachoma prevention have shaped the current approach to vaccines for sexually transmitted chlamydia. Human trials demonstrated that parenteral immunization with whole inactivated chlamydial elementary bodies induced short-lived $\left(<1\right.$ year) protection. ${ }^{68}$ Presently nearly 800 proteins are, in principal, vaccine candidates.

\section{Treponema pallidum}

Achieving effective acquired immunity to $\mathrm{T}$. pallidum is strongly supported by four lines of evidence: (1) only one-third of the untreated human syphilis patients develop late complications ${ }^{69} ;(2)$ "chancre immunity" to reinfection is observed during the early stages of active, untreated infection and is associated with strong humoral and CMI responses $^{70}$; (3) human experiments have shown that, after intradermal challenge, the development of lesions and changes in syphilis serology were dependent on the length of prior infection and that untreated, infected subjects developed no lesions or serologic changes ${ }^{71}$; and (4)supporting evidence exists in animal models. ${ }^{70}$ Vaccine research is focused on recombinant treponemal antigens and proteins especially TROMPS (Treponema rare outer membrane proteins) which mediate attachment, invasion, acquisition of nutrients and cell stability. Candidates include Tp92 which promotes opsonization and phagocytosis and is 95-100\% conserved across strains.

\section{Reference:}

1. Eng TR, Butler WT, eds. The Hidden Epidemic: Confronting Sexually Transmitted Diseases. Institute of Medicine. Washington, DC: National Academy Press, 1997.

2. World Health Organization (WHO). Sexually Transmitted Infections - Fact sheet. Geneva: World Health Organisation, 2005.

3. AbouZahr C, Vaughan JP. Assessing the burden of sexual and reproductive ill-health: questions regarding the use of disability-adjusted life years. Bull World Health Organ 2000; 78(5): 655-666.

4. Rottingen JA, Cameron DW, Garnett GP. A systematic review of the epidemiologic interactions between classic sexually transmitted diseases and HIV: how much really is known? Sex Transm Dis 2001; 28(10): 579-597.

5. Fleming DT, Wasserheit JN. From epidemiological synergy to public health policy and practice: the contribution of other sexually transmitted diseases to sexual transmission of HIV infection. Sex Transm Infect 1999; 75: 3-17.

6. Reitmeijer CA. Risk reduction counselling for prevention of sexually transmitted infections: how it works and how to make it work. Sex Transm Infect 2007; 83: 2-9.

7. Manhart LE, Holmes KK. Randomized controlled trials of individual-level, population-level, and multilevel interventions for preventing sexually transmitted infections: what has worked. J Infect Dis 2005; 191(Suppl 1): S7-S24.

8. Hollinger FB, Liang TJ, Hepatitis B virus, in Knipe DM et al., eds. Fields Virology, 4th edn. Philadelphia, PA Lippincott Williams \& Wilkins, 2001, p. 2971.

9. Shouval D. Hepatitis B vaccines. J Hepatol 2003; 39(Suppl 1): S70-S76.

10. Rehermann B. Immune responses in hepatitis B virus infection. Semin Liver Dis 2003; 22(1): 21 37.

11. Bertoletti A, Ferrari C. Kinetics of the immune response during $\mathrm{HBV}$ and $\mathrm{HCV}$ infection. Hepatology 2003; 38: 4-13.

12.Pumpens P, Grens, E, Nassal M. Molecular epidemiology and immunology of hepatitis B virus infection: an update. Intervirology 2002; 45: 218232.

13.Lok AS. Chronic hepatitis B. N Eng1 J Med 2002; 346(22): 1682-1683.

14.CDC. Quadrivalent human papillomavirus vaccine. MMWR 2007; 56: 1-23.

15.Koutsky LA, Ault KA, Wheeler CM, et al. A controlled trial of a human papillomavirus type 16 vaccine. N Engl J Med 2002; 347: 1645-1651.

16. The National Advisory Committee on Immunization (Canada). Can Commun Dis Rep 2007; 33: 1-32.

17. Stanley M. Prophylactic HPV vaccines. J Clin Pathol published online 26 Jan 2007, doi: 10.1136/jcp.2006.040568.

18. Block SL, Nolan T, Sattler C, et al. Comparison of 
the immunogenicity and reactogenicity of a prohylactic quadrivalent human papillomavirus (types $6,11,16,18) \mathrm{L} 1$ virus-like particle vaccine in male and female adolescents and young adult women. Pediatr 2006; 118: 2135-2145.

19. Harper DM, Franco EL, Wheeler C, et al. Efficacy of a bivalent $\mathrm{L} 1$ virus-like particle vaccine in prevention of infection with human papillomavirus type 16 and 18 in young women: a randomized controlled trial. Lancet $2004 ; 364(9447)$ : 17571765.

20. Koutsky LA, Harper DM. Current findings from prophylactic HPV vaccine trials. Vaccine 2006; 24(Suppl 3): 114-121.

21.Villa LL, Costa RL, Petta C, et al. Prophylactic quadrivalent human papillomavirus (types 6,11 , 16 , and 18) L1 virus-like particle vaccine in young women: a randomized double-blind placebocontrolled multicentre phase II efficacy trial. Lancet Oncol 2005; 6(5): 271-278.

22.Garland SM, Hernandez-Avila M, Wheeler CM, et al. Quadrivalent vaccine against human papillomavirus to prevent anogenital disease. $\mathrm{N}$ Engl J Med 2007; 356: 1928-1943.

23. The FUTURE II Study Group. Quadrivalent vaccine against human papillomavirus to prevent high-grade cervical lesions. N Engl J Med 2007; 356: 19151927.

24.Joura EA, Leodolter S, Hernandez-Avila M, et al. Efficacy of a quadrivalent prophylactic human papillomavirus (types $6,11,16,18$ ) L1 virus-likeparticle vaccine against high-grade vulval and vaginal lesions: a combined analysis of three randomised clinical trials. Lancet 2007; 367: 16931702 .

25. The FUTURE II Study Group. Effect of prophylactic human papillomavirus $\mathrm{L} 1$ virus-like-particle vaccine on risk for cervical intraepithelial neoplasia grade 2 , grade 3 , and adenocarcinoma in situ: a combined analysis of four randomised clinical trials. Lancet 2007; 369: 1861-1868.

26.Brown D, The FUTURE Study Group. HPV type 6/11/16/18 vaccine: first analysis of cross-protection against persistent infection, cervical intraepithelial neoplasia (CIN), and adenocarcinoma in situ (AIS) caused by oncogenic HPV types in addition to 16/18. Presented at 47th Annual Interscience Conference on Antimicrobial Agents and Chemotherapy (ICAAC). September 17-20, 2007. Chicago.

27.Kirnbauer R, Hubbert NL, Wheeler CM, et al. A virus-like particle enzyme-linked immunosorbent assay detects serum antibodies in a majority of women infected with human papillomavirus type 16. J Natl Cancer Inst 1994; 86: 494-499.

28. Schiller JT, Nardelli-Haefliger D. Second generation HPV vaccines to prevent cervical cancer. Vaccine 2006; 24(Suppl 3): S147-S153.

29. Cunnigham AL, Mikloska $Z$. The holy grail: immune control of human herpes simplex virus infection and disease. Herpes 2001; 8(Suppl 1): 6A-10A.

30. Morrison LA. Vaccines against genital herpes: progress and limitations. Drugs 2002; 62(8): 11191129.

31. Koelle DM, Corey L. Recent progress in herpes simplex virus immunobiology and vaccine research. Clin Microbiol Rev 2003; 16(1): 96-113.

32.Aurelian L. Herpes simplex virus type 2 vaccines: new ground for optimism? Clin Diagn Lab Immunol 2004; 11: 437-445.

33. Casanova G, Cancela R, Alonzo L, et al. A doubleblind study of the efficacy and safety of the ICP10deltaPK vaccine against recurrent HSV-2 infection. Cutis 2002; 70(4): 205-206.

34. Stanberry LR, Cunningham AL, Mindel A, et al. Prospects for control of herpes simplex virus disease through immunization. Clin Infect Dis 2000; 30: 549-566.

35. Stanberry LR. Clinical trials of prophylactic and therapeutic herpes simplex virus vaccines. Herpes 2004; 11(Suppl 3): 161A-169A.

36. Burton DR, Stanfield RL, Wilson IA. Antibody vs. HIV in a clash of evolutionary titans. Proc Natl Acad Sci U S A 2005; 102: 14943-14948. 37. Garber DA, Silvestri G, Feinberg MB. Prospects for an AIDS vaccine: three big questions, no easy answers. Lancet Infect Dis 2004; 4: 397-413.

38. Mehandru S, Wrin T, Galovich J, et al. Neutralization profiles of newly transmitted human immunodeficiency virus type 1 by monoclonal antibodies 2G12, 2F5, and 4E10. J Virol 2004; 78: 14039-14042.

39. Safrit JT. HIV vaccines in infants and children: past trials, present plans and future perspectives. Curr Mol Med 2003; 3: 303-312.

40. Trkola A, Kuster H, Rusert P, et al. Delay of HIV1 rebound after cessation of antiretroviral therapy through passive transfer of human neutralizing antibodies. Nat Med 2005; 11: 615-622.

41.Pantophlet R, Wilson IA, Burton DR. Improved design of an antigen with enhanced specificity for the broadly HIV-neutralizing antibody b12. Protein Eng Des Sel 2004; 17: 749-758.

42. Gilbert PB, Chiu YL, Allen M, et al. Long-term safety analysis of preventive HIV-1 vaccines evaluated in AIDS vaccine evaluation group NIAIDsponsored Phase I and II clinical trials. Vaccine 2003; 21: 2933-2947.

43.de Bruyn G, Rossini AJ, Chiu YL, et al. Safety profile of recombinant canarypox HIV vaccines. Vaccine 2004; 22: 704-713.

44. Gupta K, Hudgens M, Corey L, et al. Safety and immunogenicity of a hightitered canarypox vaccine in combination with rgp 120 in a diverse population of HIV-1-uninfected adults: AIDS Vaccine Evaluation Group Protocol 022A. J Acquir Immune Defic Syndr 2002; 29: 254-261.

45. Williams SB, Flanigan TP, Artenstein AW, et al. CCR5 genotype and human immunodeficiency virus (HIV)-specific mucosal antibody in seronegative women at high risk for HIV infection. J Infect Dis 1999; 179: 1310-1312.

46. Skurnick JH, Palumbo P, DeVico A, et al. Correlates of nontransmission in US women at high risk of human immunodeficiency virus type 1 infection through sexual exposure. J Infect Dis 2002; 185 : 428-438.

47.Beyrer C, Artenstein AW, Rugpao S, et al. Epidemiologic and biologic characterization of a cohort of human immunodeficiency virus type 1 
highly exposed, persistently seronegative female sex workers in northern Thailand. Chiang Mai HEPS Working Group. J Infect Dis 1999; 179: 59 67.

48. Kaul R, Trabattoni D, Bwayo JJ, et al. HIV-1specific mucosal IgA in a cohort of HIV-1-resistant Kenyan sex workers. AIDS 1999; 13: 23-29.

49. Ghys PD, Belec L, Diallo MO, et al. Cervicovaginal anti-HIV antibodies in HIV-seronegative female sex workers in Abidjan, Cote d'Ivoire. AIDS 2000; 14: 2603-2608.

50.Wright PF, Mestecky J, McElrath MJ, et al. Comparison of systemic and mucosal delivery of 2 canarypox virus vaccines expressing either HIV1 genes or the gene for rabies virus $\mathrm{G}$ protein. $\mathrm{J}$ Infect Dis 2004; 189: 1221-1231.

51. Whitney JB, Ruprecht RM. Live attenuated HIV vaccines: pitfalls and prospects. Curr Opin Infect Dis 2004; 17: 17-26.

52. Murphey-Corb M, Martin LN, Davison-Fairburn $\mathrm{B}$, et al. A formalininactivated whole SIV vaccine confers protection in macaques. Science $1989 ; 246$ : 1293-1297.

53.Pitisuttithum $P$, Gilbert $P$, Gurwith $M$, et al. Randomized, double-blind, placebo-controlled efficacy trial of a bivalent recombinant glycoprotein 120 HIV-1 vaccine among injection drug users in Bangkok, Thailand. J Infect Dis 2006; 194: 16611671.

54.Amara RR, Villinger F, Altman JD, et al. Control of a mucosal challenge and prevention of AIDS by a multiprotein DNA/MVA vaccine. Science 2001; 292: 69-74.

55. Franchini G, Gurunathan S, Baglyos L, Plotkin S, Tartaglia J. Poxvirusbased vaccine candidates for HIV: two decades of experience with special emphasis on canarypox vectors. Expert Rev Vaccines 2004; 3: S75-S88.

56. Russell ND, Graham BS, Keefer MC, et al. Phase 2 study of an HIV-1 canarypox vaccine (vCP1452) alone and in combination with rgp120: negative results fail to trigger a phase 3 correlates trial. J Acquir Immune Defic Syndr 2007; 44: 203-212.

57.Follow up of Thai adult volunteers with breakthrough HIV infection after participation in a preventive HIV vaccine trial.1-24-2007. Available at: http://www.clinicaltrials.gov/ct/show/ NCT00337181?order=2. Accessed April 24, 2007.

58.Casimiro DR, Chen L, Fu TM, et al. Comparative immunogenicity in rhesus monkeys of DNA plasmid, recombinant vaccinia virus, and replicationdefective adenovirus vectors expressing a human immunodeficiency virus type $1 \mathrm{gag}$ gene. J Virol 2003; 77: 6305-6313.

59. Shiver JW, Emini EA. Recent advances in the development of HIV-1 vaccines using replicationincompetent adenovirus vectors. Annu Rev Med 2004; 55: 355-372.

60. Santra S, Seaman MS, Xu L, et al. Replicationdefective adenovirus serotype 5 vectors elicit durable cellular and humoral immune responses in nonhuman primates. J Virol 2005; 79: 6516-6522.

61.http://www.stepstudies.com

62.www.accessmedicine.com

63. Singh M, Srivastava I. Advances in vaccine adjuvants for infectious diseases. Curr HIV Res 2003; 1: 309-320.

64. Kojima Y, Xin KQ, Ooki T, et al. Adjuvant effect of multi-CpG motifs on an HIV-1 DNA vaccine. Vaccine 2002; 20: 2857-2865.

65. Calarota SA, Weiner DB. Enhancement of human immunodeficiency virus type 1-DNA vaccine potency through incorporation of T-helper 1 molecular adjuvants. Immunol Rev 2004; 199: 8499.

66. Hook EW III, Holmes KK. Gonococcal infections. Ann Intern Med 1985; 102: 229-243.

67. Tramont EC. Gonococcal vaccines. Clin Microbiol Rev 1989; 2(Suppl): S74-S77.

68. Grayston JT, Wang SP. The potential for vaccine against infection of the genital tract with Chlamydia trachomatis. Sex Transm Dis 1978; 5(2): 73-77.

69. Sparling PF, Elkins C, Wyrick PB, et al. Vaccines for bacterial sexually transmitted infections: a realistic goal? Proc Natl Acad Sci U S A 1994; 91(7): 2456-2463.

70. Stamm LV. Biology of Treponema pallidum, In: Holmes KK, Sparling PF, Mardh P-A, et al., eds. Sexually Transmitted Diseases, 3rd edn. New York: McGraw-Hill, 1999, p. 467.

71.Magnuson HJ, Thomas EW, Olansky S, et al. Inoculation syphilis in human volunteers. Medicine 1956; 35: 33-82. 